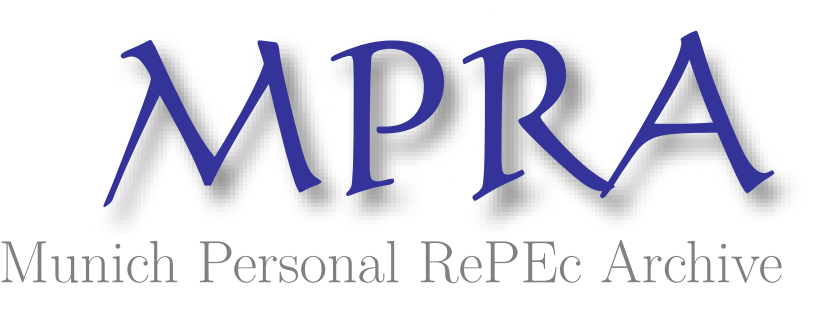

\title{
Healthcare reform in Italy: an analysis of efficiency based on nonparametric methods
}

De Nicola, Arianna and Gitto, Simone and Mancuso, Paolo

Dipartimento di Ingegneria dell'Impresa, Università di Roma "Tor Vergata"

June 2011

Online at https://mpra.ub.uni-muenchen.de/68690/

MPRA Paper No. 68690, posted 07 Jan 2016 07:29 UTC 


\title{
A two-stage DEA model to evaluate the efficiency of the Italian health system ${ }^{1}$
}

\author{
Arianna De Nicola ${ }^{a}$, Simone Gitto ${ }^{b}$, Paolo Mancuso ${ }^{c}$. \\ ${ }^{a}$ De Nicola: Dipartimento di Ingegneria dell'Impresa. Università di Roma "Tor Vergata", Via del \\ Politecnico 1, 00133 Rome, Italy; e-mail arianna.de.nicola@uniroma2.it \\ ${ }^{\mathrm{b}}$ Gitto: Dipartimento di Ingegneria dell'Impresa. Università di Roma "Tor Vergata", Via del \\ Politecnico 1, 00133 Rome, Italy; e-mail simone.gitto@uniroma2.it \\ ${ }^{\mathrm{c}}$ Mancuso: Dipartimento di Ingegneria dell'Impresa. Università di Roma "Tor Vergata", Via del \\ Politecnico 1, 00133 Rome, Italy; e-mail paolo.mancuso@uniroma2.it
}

\begin{abstract}
Over the past twenty years, important changes in the Italian health system have led to different approaches in organizing, delivering and financing health services throughout the regions of the country. This study aims to examine the impact these factors have had on efficiency. The methodology adopted is based on the developments in bootstrapping Data Envelopment Analysis (DEA). In particular, employing a two-stage procedure, we analyzed the impact that political interventions have produced on healthcare efficiency. The data, which were at the local health unit level for the period 2004-2005, were aggregated to the provincial level in order to take into account patient mobility. The study reveals that the organizational model adopted by the Lombardia region allows for the best results in healthcare efficiency. Second, administrative decentralization from the regional governments to local health units is a source of inefficiency. Third, adjusting the cost of delivering care, by taking into consideration regional health characteristics, improves efficiency. Finally, future policy interventions should make careful valuations of the impacts of patient mobility on healthcare efficiency.
\end{abstract}

Keywords: healthcare efficiency, two-stage estimation, Data Envelopment Analysis, patient mobility, bootstrap.

\footnotetext{
${ }^{1}$ An earlier version of this paper was presented at theXII European Workshop on Efficiency and Productivity Analysis (EWEPA). Verona, Italy, June 22-24, 2011.
} 


\section{Introduction}

The Italian National Health Service (Servizio Sanitario Nazionale, SSN) is funded by tax revenue and aims to ensure essential health care services (LEAs) for all Italian citizens and foreign legal residents. SSN, created in 1978 along the lines of the British National Health service [1], has undergone several reforms aimed at increasing its institutional and financial autonomy and introducing competition in the provision of health services. Understanding the impact that policy decisions have had on healthcare efficiency is crucial to identify the best practices in the management of public health services in Italy. To study these questions, we employed recent advances in DEA that allow, through the bootstrap technique, for inferences based on DEA measures [2]. Most of the current literature we examined did not consider the possibility of making inferences based upon DEA results. Applying DEA, Retzlaff-Roberts et al. [3] studied the health care efficiencies of 27 OECD countries to identify the best health systems. Similarly, the papers by Aletras et al. [4], Kotodimopoulos et al. [5] and Linna et al. [6] used DEA analysis to investigate the efficiencies of the national health systems of Greece, Finland and Norway, respectively. A limited number of papers used the non-parametric techniques in an inferential setting $[7,8,9]$.

In the literature focused on the Italian health care system, Barbetta et al. [10] found a decline in technical efficiency, mainly due to public policies aimed at reducing hospitalization rates. Additionally, Daidone et al. [11] restricted their analysis to the hospitals in a particular region and concluded that the organizational structure and level of specialization of the hospitals in question heavily affected technical efficiency. The remaining papers on the Italian health system discussed the effects of different approaches to reform. In particular, Tediosi et al. [12] pointed out that the central government has an important role in containing healthcare expenditures and helping in the enforcement of decentralization. They also highlighted that when there are differences in administrative and policy skills, decentralization may lead to undesirable divergent evolution paths. Ferrario et al. [13] concluded that the process of fiscal and administrative decentralization raises policy issues concerning the different health care spending possibilities across regions and the impact on interregional patient mobility. Gitto [14] examines change in productivity 
experienced by Italian Hospitals between 2001 and 2005. He find evidence of decreased productivity over the sample period as well as technological regress.

Departing from previous studies on the Italian SSN, this present paper employs the new semiparametric technique developed by Simar and Wilson [2] to assess the efficiency of the Italian health system at the provincial level. Moreover, it attempts to address questions concerning the impact that organizational models, reimbursement systems and patient mobility have on healthcare efficiency.

In the next Section, we introduce the Italian health care system. Section 3 discusses the methodology used in our empirical analysis. Data and variables are described in Section 4, and in Section 5, we present the empirical findings. Section 6 offers some concluding remarks and discussion.

\section{The Italian health care system}

The Italian SSN is made up of three decision makers: 1) the central government, 2) the 21 regional governments ${ }^{2}$ and 3 ) the local health units. (see $[15,16]$ for a more extensive discussion).

The local health units in Italy comprise a number of organizations: local health enterprises (Aziende Sanitarie Locali, ASL), public hospital enterprises (Aziende Ospedaliere, AO), National Institutes for Scientific Research and private accredited providers (for-profit and not-for-profit). $\mathrm{ASLs}^{3}$ are public providers that are responsible, on a territorial basis, for assessing healthcare needs and providing a full range of direct services either through their own facilities or by purchasing such services from the $\mathrm{AOs}^{4}$, research hospitals ${ }^{5}$ or accredited private hospitals. ${ }^{6}$ This territorial configuration resulted from several reforms begun in 1992, which have led to this regionalization and the application of the theory of managerialism in the provision of health care

\footnotetext{
${ }^{2}$ The Italian Constitution defines 20 regions, but the SSN divides the Trentino Alto Adige region into two areas: Bolzano and Trento.

${ }^{3}$ In 2005, there were 195 ASLs (www.salute.gov.it). The number of inhabitants assigned to each ASL ranges from 50,000 to 200,000 .

${ }_{5}^{4}$ In 2005, there were 102 AOs ( www.salute.gov.it ). AOs provide highly specialized tertiary hospital care.

${ }^{5}$ In 2006, the National Institutes for Scientific Research comprised a network of 10 public university Policlinics and 55 Institutes for scientific care and treatment (www.salute.gov.it).

${ }^{6}$ In 2009, ASLs contracted out services to 553 private hospitals [15].
} 
services. The reforms have created the existence of a quasi-market mechanism and have increased the power of the central government in determining quality standards [16]. Moreover, the reforms have strengthened the principle of a prospective payment system (PPS) based on DiagnosisRelated Group (DRG). They have also established financing schemes for specific activities by requiring all health structures to be financed by predefined budgets composed of two elements: a payment for inpatient and outpatient care dictated by predefined rates based on DRG and a payment based on the average costs to deliver care [15].

The central government sets the general objectives and fundamental principles for the national health care system. Each year, it defines the set of LEAs that must be provided uniformly throughout the country and determines the standard costs for these services. The funds collected by the central government, through general and payroll taxes, for the provision of LEAs are allocated to the regional units on an adjusted capitation basis. The central government also sets the standard rate of payment for treatment based upon the average cost of delivering care to a patient with that condition and assigns a specific weight ${ }^{7}$ to each DRG.

regional governments are responsible for legislative and administrative health functions, planning health care activities, organizing supply in relation to population needs and monitoring quality, appropriateness and efficiency of the services provided [15]. The regional governments have the power to raise taxes, which allows them to provide health services in addition to those defined in the LEA [17]. Moreover, these governments can modify the tariffs set by the central government to accommodate the characteristics of the particular health organizations in their regions. The greater independence given to the regional governments has accelerated the fragmentation of reimbursement systems and the organization of regional services within the healthcare system [18].

Currently, there are three alternative reimbursement systems applied by different regional governments in Italy [19]:

\footnotetext{
${ }^{7}$ The weight reflects the average level of resources used by an average medicare patient in the DRG relative to the average level of resources used by all medicare patients.
} 
$\checkmark$ "cost adjusted": the national DRG weights are used, but the national average costs to deliver care are adjusted to reflect regional characteristics of the health organization and population health structure;

$\checkmark$ "analytic": the average cost to deliver care to a patient with a particular disease is measured by analyzing the costs from a sample set of the regional hospitals, and the resulting average cost is then applied to each DRG;

$\checkmark$ "national": the national DRG cost table is adopted; however, under this system there remains variation among a small number of specific DRGs, which reflects peculiarities across different types of regional hospitals.

According to Jommi [18, 20] and Mazzei [19], there are also three readily identifiable organizational models (see Figure 1):

$\checkmark$ "ASL centred template": the regional government finances ASLs on a capitation basis. ASLs sign service agreements with public and private accredited providers.

$\checkmark$ "Region centred template": the regional government exercises a purchaser role, and it finances providers directly based on their activity. This governance form reduces the autonomy of the ASLs.

$\checkmark$ "Purchaser-provider split template": there is a separation between purchasers and providers. Private accredited providers and AOs are the only organizations available to offer services, and they are reimbursed though tariffs. In this organizational model, AOs and private accredited hospitals act as providers of services, and ASLs act as purchasers. This model is only used in the Lombardia region.

\section{(Insert Figure 1 about here)}

Other key factors concern the reduction of the number of ASLs (from 659 in 1992 to 195 in 2005) to gain scale advantages, the right for the patients to be admitted to any local health unit, even if it is outside their district of residence and the introduction of the law on federalism (Legislative Decree 56/2000), which has enabled regional governments to finance public services through 
regional taxes. These factors might have a significant impact on the SSN. In fact, poor regions, characterized by lower tax revenues, may be unable to guarantee the same services provided by other regions, in terms of quality and/or quantity, thus contributing de facto to their patient outflows [21] (see Table 1). Furthermore, the economic compensation among regions due to interregional patient mobility could undermine the main pillar of the SSN because the lowincome regions might prove unable, without central government intervention, to ensure a minimum level of quality in their healthcare system. Therefore, considering the impact caused by patient mobility may shed new light on the efficiency of the Italian SSN. Unfortunately, data on patient mobility are not available at the level of the health organization (e.g. ASL, AO) but only at the level of the province, which is a territorial and administrative division between municipality and region.

We now focus our analysis on the provinces ${ }^{8}$ and as consequence, merge the data regarding health organizations within the same province.

\section{(Insert Table 1 about here)}

\section{Methodology}

To analyze the effect of environmental variables on provincial healthcare efficiency, we employed a two-stage procedure. In the first stage, we estimated healthcare efficiency from 2004 to 2005 for each province through DEA [22]. Following the related literature on the argument $[10,23,24]$, we adopted an output-oriented model. The output-oriented model was preferable because in Italy, as in other countries, the policy focus on reducing the public deficit has compelled health organizations to keep the amount of resources consumed constant, even while increasing the extent of health services provided.

Moreover, we made use of standard assumptions about the production set to analyze efficiency in an inferential setting [25]. The traditional DEA-estimator is biased by construction, and it is affected by uncertainty due to sample variation $[2,25,26]$. To remove these drawbacks, we

\footnotetext{
${ }^{8}$ In 2005, there were 103 provinces in Italy.
} 
applied the procedure based on the bootstrap technique proposed by Simar and Wilson [26] to derive the sampling distributions and to construct confidence intervals. In the second stage, again following Simar and Wilson [2], we ran truncated regressions in a bootstrap setting to assess the effects of environmental variables on healthcare efficiency.

To facilitate the interpretation of the results in the following sections, it is useful to recall that in the output-orientated DEA model, under the hypothesis of variable return to scale (VRS), an efficiency score $\hat{\mathrm{D}}_{\mathrm{it}}$ is calculated for each decision making unit (DMU) $i(i=1,2, \ldots \mathrm{n})$ at time $\mathrm{t}$ $(t=1,2, \ldots, \mathrm{T})$ by solving the following linear program:

$$
\begin{aligned}
\hat{\theta}_{i t}=\left[\hat{D}_{i t}\right]^{-1}=\max _{\theta \lambda} \theta & \\
\text { s.t. } \quad & \mathrm{x}_{\mathrm{it}} \geq X_{t} \lambda \\
& \theta \mathrm{y}_{i t} \leq Y_{t} \lambda \quad i=1,2 \ldots, n ; \quad t=1,2 \ldots, T \\
& 1^{\prime} \lambda=1 \\
& \lambda \geq 0
\end{aligned}
$$

In this equation, $\hat{\theta}_{i t}$ and $\hat{D}_{\text {it }}$ are the Farrell [27] and Shepard [28] distance functions, $n$ is the number of DMUs and $T$ is the number of time periods; $\mathbf{Y}_{\mathrm{t}}$ is an $s x n$ matrix of $s$ outputs, $\mathbf{X}_{\mathrm{t}}$ is an $r x n$ matrix of $r$ inputs, $\lambda$ represents a $n x l$ vector of weights which may obtain a convex combination between inputs and outputs and $\mathbf{1}$ ' is a vector of ones.

$\hat{\theta}_{i t}$ is an inefficiency measure and always assumes values equal to or greater than one. As opposite, $\hat{\mathrm{D}}_{\mathrm{it}}$ is an efficiency measure, and it assumes values between zero and one. DMUs with efficiency scores equal to one are located on the frontier, and as a consequence, their outputs cannot be further expanded without a corresponding increase in inputs.

However, this relationship (Equation 1) did not allow us to determine whether the efficiency values are real or merely an artifact of the fact that we did not know the true production frontiers and had to estimate them from a finite sample [25]. Therefore, following the authors cited above, we employed a consistent bootstrap estimation procedure in order to correct the efficiency scores. The idea underlying the bootstrap is to approximate the sampling distributions of $\hat{\theta}$ by simulating their data generating processes (DGP). In other words, given the estimates $\hat{\theta}_{i t}$ of the unknown 
true values of $\theta_{i t}$, through the DGP processes, we generated a series of pseudo-datasets to obtain the bootstrap estimate, $\hat{\theta}_{i t}^{*}$. If the bootstrap is consistent, then:

$$
\left(\hat{\theta}_{i t}-\theta_{i t}\right) \mid S \stackrel{\text { approx }}{\sim}\left(\hat{\theta}_{i t}^{*}-\hat{\theta}_{i t}\right) S^{*} \quad i=1,2, \ldots, n t=1,2, \ldots, T
$$

In this equation, $S$ and $S^{*}$ denote the observed and the bootstrap samples, respectively. We used the smooth bootstrap procedure proposed by Simar and Wilson [26] to obtain sampling distribution of efficiency score, through which we derived the bias-corrected confidence intervals. The econometric model in our two-stage analysis takes the form of a truncated regression model:

$$
\hat{\theta}_{\mathrm{it}}=\mathbf{z}_{\mathrm{it}} \boldsymbol{\beta}+\varepsilon_{\mathrm{it}} \quad i=1,2, \ldots, n ; t=1,2, \ldots, T
$$

Here $\hat{\theta}_{i t}$ are obtained by (Equation 1), $\mathbf{z}_{\mathrm{it}}$ is a set of explained variables for each unit $i$ at time $t$, and $\varepsilon_{\mathrm{it}}$ is $\mathbf{N}(0, \sigma)$ with left-truncation at $\mathbf{1}-\mathbf{z}_{\mathrm{it}} \boldsymbol{\beta}$.

Traditional second-stage approaches suffer from various deficiencies. To overcome these problems, the regression parameters were estimated by truncated regression with a double bootstrap method [2]. The algorithm was implemented through the FEAR software library [29] linked to the statistical package $\mathrm{R}$.

\section{Data and variables}

Data were collected from the Italian Ministry of Health ${ }^{9}$ and from the "Health for All" database. ${ }^{10}$ They covered the period 2004-2005 and were the most recently available data. Because the decision making unit in question is the province, the data about ASLs, AOs, the National Institutes for Scientific Research and private accredited hospitals were aggregated to the provincial level. After eliminating the observations with missing values, the sample consists of a balanced panel of 101 provinces $^{11}$. Using provinces as decision making units allows for a homogeneous comparison among production units. These comparisons were facilitated by the fact that the regional governments allocate healthcare resources at the provincial level by taking into account population needs [15].

\footnotetext{
${ }^{9}$ WwW.ministerosalute.it

${ }^{10}$ www.istat.it

${ }^{11}$ Two provinces, Gorizia and Terni, are not in the sample.
} 
We specified three inputs (physicians, nurses and number of beds) and two outputs (number of total patients and number of inpatient days). The inputs and outputs are measured in terms of physical quantities, as no reliable price data are available. The physicians input is measured by the number of salaried physicians and dentists; the nursing input is measured by the number of paid nurses. Because direct measurement of capital in health care industry is problematic, we used the number of beds as a proxy for capital investment [30, 31].

The empirical literature regarding the estimation of efficiency in health care strongly suggests that the number of total patients (measured in this paper by the sum of total discharged patients) is the most reliable measure of output $[9,32]$. Because the inpatient admission is related to the tariff scheme [15], we considered also the number of inpatient days as output $[33,34]$ in order to account for the differences arising from the adoption of alternative reimbursement systems. Additionally, inpatient admission is more resource intensive than ambulatory care, and taking both of these aspects into account may help to explain the varying input usage by different health organizations.

To consider the severity of the illness treated or the intensity of treatment received, outputs were multiplied by the case-mix index (ICM) $[33,35]$. The performance of the healthcare system is influenced by external factors that managers cannot control but can impact efficiency. Although we did not use all these environmental variables to construct the frontier, they are clearly relevant in the second stage in order to assess their impact on healthcare efficiency. In particular, we considered six environmental variables: the organizational model, the reimbursement system, the total patients outflow, the total patients inflow, the interregional patients outflow and the interregional patients inflow. The different types of organizational models are described by two dummies. The first indicates if the organization structure is a purchaser-provider split template, and the second indicates if the region adopted an ASL centred template. To capture the effects of the different reimbursement systems used by the regions, we included two further dummies. The first shows if the reimbursement system adopted is national and the second if it is analytic. The variables total patients outflow, total patients inflow, interregional patients outflow and interregional patients inflow describe the different typologies of patient mobility that might affect 
healthcare efficiency. Total patients outflow and inflow measure both movements among provinces within the same region and movements among provinces in different regions. Through these variables, we considered, at the provincial level, the impact that patient mobility has on efficiency. However, as mentioned above in Section 2, the quality and the quantity of the services offered may differ among regions because only a minimum level of care must be guaranteed. Moreover, the differences among the offered health services have been increased by the law on fiscal federalism, which affects the capacity of regional governments to finance public services $[20,36]$. Thus, to take into account of differences in quality and quantity in the health services offered, we introduced the variables interregional patients inflow and outflow, which describe patient mobility among provinces in different regions, into the analysis. Finally, a dummy variable year was included as a control variable.

Combining the two alternative output specifications and the two measures of patient mobility, we obtained four different models to assess the efficiency of the Italian health system at the provincial level (see Table 2).

\section{(Insert Table 2 about here)}

Table 3 presents some descriptive statistics for the inputs and the outputs used in DEA and for the continuous variables employed in the two-stage regressions.

\section{(Insert Table 3 about here)}

An analysis of Table 3 shows that the data are right skewed, which supports our choice to use a non-parametric estimator, as discussed by Wilson and Carey [37].

\section{Estimation results}


We estimated efficiency scores associated with the two different DEA models ${ }^{12}$ following the methodology defined in Section 3. The results were obtained from 2,000 bootstrap iterations. In Figure 2, the bootstrap estimates of confidence intervals for efficiency are classified by the three organizational models and sorted by their lower bounds. Results for the ASL centred template and the Region centred template appeared quite similar in distribution, whereas provinces adopting the purchaser-provider split template, characterized by confidence intervals more closed to the frontier, showed the best results in efficiency.

\section{(Insert Figure 2 about here)}

To better investigate the above evidence, we ran the adapted Li test for equality of efficiency distribution [38], as modified by Simar and Zelenyuk [39]. The null hypothesis of equal distribution of efficiency scores among organizational models was rejected at a $1 \%$ significance level for all of the cases (see Table 4). This implies that a significant difference exists among the distributions of the three organizational models.

\section{(Insert Table 4 about here)}

The Lombardia region is the only one that has adopted the purchaser-provider split template model, and as reported in Table 1, its SSN expenditures per capita are lower than the mean expenditures of the other Italian regions. In Lombardia, the ASLs are characterized by a high degree of autonomy in both organization and the management of health services. However, this autonomy has been bounded by stricter financial requirements, and these features have contributed to the ability of the region to guarantee higher standards of health services to be offered to patients $[40,41]$.

Second stage results ${ }^{13}$ from the double bootstrap estimation are presented in Table 5.

\footnotetext{
${ }^{12}$ DEA efficiency scores are the same for models $A$ and $B$ and for models $C$ and D (see Table 2).

${ }^{13}$ Because Simar and Wilson [2]'s algorithm employs the Farrell measure of efficiency, parameters with a negative sign indicate sources of efficiency and those with a positive sign indicate sources of inefficiency.
} 


\section{(Insert Table 5 about here)}

An analysis of the results in model $A$ shows that the coefficient of the total patients outflow and inflow are statistically significant at a $10 \%$ level and are of opposite signs. In particular, while the total patients inflow increases the efficiency of a health organization at the provincial level, the total patients outflow reduces it. This result implies that, on average, the Italian provinces should reduce their health productive inputs. The organizational model, purchaser-provider split template, allows for efficiency gains when compared with the Region and the ASL centred template models, confirming the evidence obtained through the analysis of the efficiencies distribution. The positive coefficient of the ASL centred template dummy indicates that the provinces located in the regions that adopt such an organizational model, are less efficient than those that have opted for a Region centred template model. Our results seem to indicate that lodging decision making regarding the healthcare system at an intermediate level between ASLs and the central government allows for better planning and control of the available resources. Thus, while a degree of decentralization from the regional governments to local health units may indeed yield substantial gains for the health system, excessively decentralized health care may lead to serious difficulties [42]. Model $B$ confirms all of the previous evidence, and it highlights the differences in the quality and quantity of the health care services offered by each region as source of inefficiency with a positive significant coefficient for the variable Interregional patients outflow and a negative significant coefficient for the variable Interregional patients inflow. Thus, a region characterized by patient mobility outside its borders should aim to increase the quality and/or the quantity of the health services it offers. However, as previously discussed, the law on fiscal federalism should avoid the "de facto" implementation of such changes to the system.

Finally, we analyzed models $C$ and $D$ in order to evaluate the impact of different reimbursement systems. The analysis of the regression results for these two additional models indicates that the national reimbursement system produces a negative and significant impact on healthcare 
efficiency. The cost adjusted system, which considers the regional health environment, allows regions to obtain a better input-output allocation. These results may be explained by the fact that defining the average cost to deliver care at national level fails to account for local characteristics related to population and health structures. The coefficient of the variable analytic is not significant, so policy conclusions regarding this variable cannot be drawn [43]. Models $C$ and $D$ confirm the previous findings for the remaining explicative variables.

\section{Conclusions and discussion}

Since 1992, a variety of reforms to the Italian SSN have aimed to transfer responsibility for organizing healthcare to the regions and to introduce the criteria advocated by managerialism into the system. Regional governments have become responsible for legislative and administrative functions, planning health care activities, organizing supply in relation to population needs and monitoring the quality, appropriateness and efficiency of the services provided. In this new environment, the regional governments have adopted different organizational models and alternative reimbursement systems. Examining the system at the level of the provinces, the territorial and administrative units of the Italian regions, this paper addresses the impact of the reforms on healthcare efficiency. This analysis was conducted by applying a two-stage DEA model. The analysis reveals that the organizational model adopted by only one region in the country, Lombardia, showed the greatest healthcare efficiency during the analyzed time span, 2004-2005. This organizational model is characterized by a well-defined separation between health service providers and purchasers, and it is based on freedom of choice for users between public and private accredited providers. Moreover, the analysis indicates that a high level of administrative decentralization does not improve the delivery of healthcare services.

Examining the three alternative reimbursement systems adopted in the Italian SSN, we observed that efficiency increases when the average cost to deliver care takes into account regional characteristics of the population and healthcare structures.

Finally, we showed that provincial healthcare efficiency is increased by the influx of patients to a region (interregional patients inflows) and is decreased by the outflow of patients from a region 
(interregional patients outflow). The impact of patient mobility among regions will probably create the greatest challenges for the central government in future years due to the administrative and fiscal decentralization occurring in Italy. In this changed context, poorer regions, which are mostly located in the South of the country, may prove unable, without central government intervention, to offer adequate levels of health services, and as a consequence, their patient outflows could increase.

Notably, our study focused on technical efficiency in healthcare systems employing physical variables and does not allow for the evaluation of allocative efficiency.

A possible improvement to the present work will assess price data and population size [44]. 


\section{References}

[1] France G, Taroni F, Donatini A. The Italian health-care system. Health Economics 2005; 14:187-202.

[2] Simar L, Wilson P. Estimation and inference in two stage, semi-parametric models of productive efficiency. Journal of Econometrics 2007;136: 31-64.

[3] Retzlaff-Roberts D, Chang C, Rubin R.M. Technical efficiency in the use of health care resources: a comparison of OECD countries. Health Policy 2004; 69: 55-72.

[4] Aletras V, Kontodimopoulos N, Zagouldoudis A, Niakas D. The short-term effect on technical and scale efficiency of establishing regional health systems and general management in Greek NHS hospitals. Health Policy 2007; 83: 236-45.

[5] Kontodimopoulos N, Nanos P, Niakasmeasures D. Balancing efficiency of health services and equity of access in remote areas in Greece. Health Policy 2006;76 (1): 49-57.

[6] Linna M, Hakkinen U, Magnussen J. Comparing hospital cost efficiency between Norway and Finland. Health Policy 2006; 77: 268-78.

[7] Halkos G.E, Tzeremes NG. A conditional nonparametric analysis for measuring the efficiency of regional public healthcare delivery: An application to Greek prefectures. Health Policy 2010; In press doi:10.1016/j.healthpol.2010.10.021 .

[8] Magnussen J, Nykan K. Measuring efficiency in clinical departments. Health Policy 2008; 87: 1-7.

[9 ] Staat M. Efficiency of hospitals in Germany: a DEA-bootstrap approach. Applied Economics 2006; 38 (19): 2255-63.

[10] Barbetta G.P, Turati G, Zago A.M. Behavioral differences between public and private not-for-profit hospitals in the Italian national health service. Health Economics 2007; 16: 75-96.

[11] Daidone S, D'Amico F. Techincal efficiency, specialization and ownership form: evidences from a pooling of Italian hospitals. Journal of productivity Analysis 2009; 32: 203-16.

[12] Tediosi F, Gabriele S, Longo F. Governing decentralization in health care under tough budget constraint: What can we learn from the Italian experience?. Health Policy 2009; 90: 303-12.

[13] Ferrario C, Zanardi A. Fiscal decentralization in the Italian NHS: What happens to interregional redistribution?. Health Policy 2010, doi:10.1016/j.healthpol.2010.08.016.

[14] Gitto S. The measurement of productivity and efficiency: theory and applications. Ph.D. Thesis. Dipartimento di Ingegneria dell’Impresa, Università degli Studi di Roma "Tor Vergata", 2008. Available at http://hdl.handle.net/2108/835.

[15] Lo Scalzo A, Donatini A, Orzella L, Cicchetti A, Profili S, Maresso A. Health Care Systems in Transition: Italy. Copenhagen: WHO Regional Office for Europe on behalf of the European Observatory on Health Systems and Policies; 2009.

[16] Donatini A, Rico A, D’Ambrosio M. G, Lo Scalzo A, Orzella L, Cicchetti A, et al. Health Care Systems in Transition: Italy. Copenhagen: WHO Regional Office for Europe on behalf of the European Observatory on Health Systems and Policies; 2001. 
[17] Fattore G, Torbica A. Inpatient reimbursement system in Italy: How tariffs relate to costs? Health Management Sci 2006; 9: 251-58.

[18] Jommi C, Cantù E., Anessi-Pessina E. New funding arrangemeents in the Italian National Health Service. International Journal of Health Planning and Management 2001; 16: 347-68.

[19] Mazzei L. I sistemi tariffari per le prestazioni di assistenza ospedaliera. Un esame della normativa nazionale e regionale. Centro studi Assobiomedica; 2005: Technical Report 9.

[20] Jommi C. I meccanismi regionali di finanziamento delle Aziende Sanitarie. In: Anessi-Pessina E, Cantù E, editors. L'aziendalizzazione della sanità in Italia, Rapporto OASI 2000. Milano.

[21] Levaggi R, Zanola R. Patients' migration across regions: the case of Italy. Applied Economics 2004; 36:1751-57.

[22] Charnes A, Cooper W.W, Rhodes E. Measuring the efficiency of decision-making units. European Journal of Operational Research 1978; 2:429-44.

[23] Ferrier G.D, Rosko M, D.Valdmanis V. Analysis of uncompensated hospital care using a DEA model of output congestion. Health Care Manage Sci 2006; 9: 181-88.

[24] Ancarani A, Di Mauro C, Giammanco M.D. The impact of managerial and organizational aspects on hospital wards' efficiency: Evidence from a case study. European Journal of Operational Research 2008.

[25] Simar L, Wilson PW. Statistical inference in non parametric frontier models: The state of art. Journal of Productivity Analysis 2000; 13: 49-78.

[26] Simar L., Wilson PW. Sensitivity analysis of efficiency scores: how to bootstrap in non parametric frontier models. Management Science 1998; 44: 49-61.

[27] Farrell M.J. The measurement of productive efficiency. Journal of Royal Statistical Society A, 1957;120: 253-81. Series A.

[28] Shepard R.W. Theory of cost and production functions. Princeton: Princeton University Press; 1970.

[29] Wilson PW. FEAR: A Software Package for Frontier Efficiency Analysis with R. Socio-Economic Planning Sciences 2007; 42 (4): 247-54.

[30] Grosskopf S, Margaritis D, Valdaminis V. Competitive effects on teaching hospitals. European Journal of Operation Research 2004; 154: 515-25.

[31] Aletras V, Kontodimopoulos N, Zagouldoudis A, Niakas D. The short-term effect on technical and scale efficiency of establishing regional health systems and general management in Greek NHS hospitals. Health Policy 2007; 83: 236-45.

[32] Siciliani, L. Estimating technical efficiency in the hospital sector with panel data: A comparison of parametric and non parametric techniques. Applied Health Economics and Health Policy 2006; 5(2): 99-116.

[33] Grosskopf S, Valdaminis V. Evaluating hospital performance with case-mix adjusted outputs. Medical Care 1993; 31(6): 525-32. 
[34] Färe, R, Grosskopf S, Norris M, Zhang Z. Productivity Growth, Technical Progress, and Efficiency Change in Industrialized Countries. American Economic Review 1994; 84: 66-83.

[35] Burges J, Wilson P.W. Hospital Ownership and Technical Inefficiency. Management Science 1996; 42(1):110-23.

[36] France G. Cross-border flows of Italian patients within the European Union: an international trade approach. European Journal of Public Health 1997; 7(3): 18-25. Supplement.

[37] Wilson P.W, Carey K. Nonparametric analysis of returns to scale and product mix among U.S. hospitals. Journal of Applied Econometrics 2004; 19: 505-24.

[38] Li Q. Nonparametric testing of closeness between two unknown distribution functions. Econometric Reviews 1996; 15: 261-74.

[39] Simar L., Zelenyuk V. On Testing Equality of Distributions of Technical Efficiency Scores. Econometric Reviews 2006; 25(4) , 497-522.

[40] Colombo A. The Lombardy model: Subsidiarity-informed Regional Governance. Social Policy \& Administration 2008; 42 (2), 177-96.

[41] Anessi-Pessina E, Cantù E, Jommy C. Phasing out Market Mechanisms in the Italian National Health Service. Public Money \& Management 2004; 309-16.

[42] Levaggi R, Smith PC. Decentralization in health care: lessons from public economics. In: Smith PC,

Ginnelly L, Sculpher M,editors. Health policy and economics. Maidenhead: Open University Press; 2005. P. 223-47.

[43] Zelenyuk V. Power of significance test of dummy variables in two stage efficiency analysis model. Applied economics Letters 2009; 16(15): 1493-95.

[44] Zavras A.L., Tsakos G., Economou C. Using DEA to Evaluate Efficiency and Formulate Policy Within a Greek National Primary Health Care Network. Journal of Medical Systems 2002; 26(4): 285-92. 
Fig. 1. Organizational models.

\section{ASL centred template}

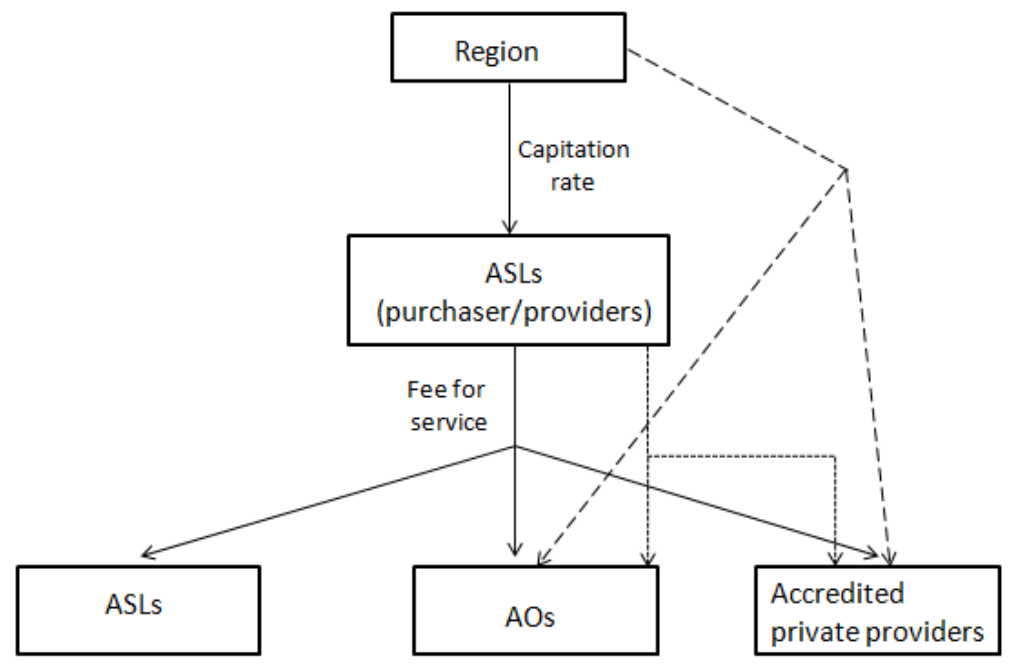

Funding flow and criteria

Regional funding caps/targets

Bilateral contracts (ASLs/AOs, accredited private providers)

\section{Region centred template}

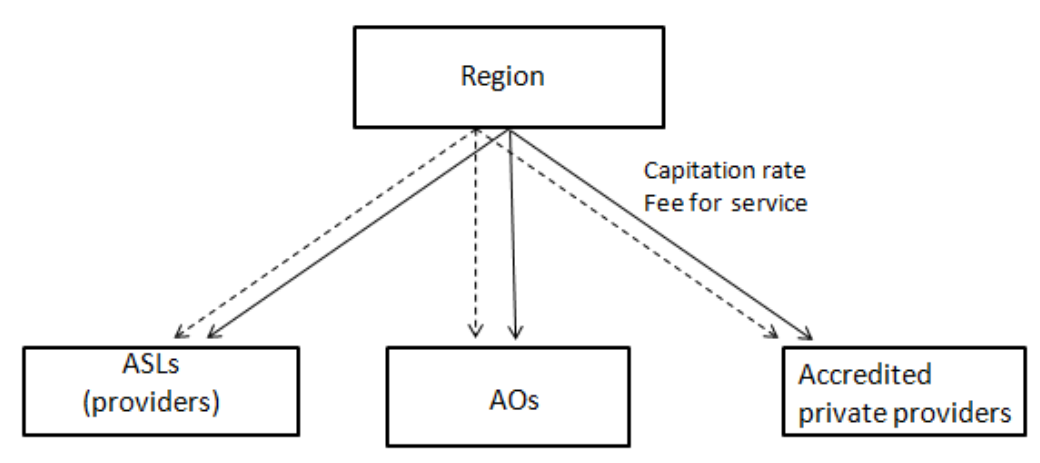

Funding flow and criteria

Regional funding caps/targets 
Purchaser-provider split template

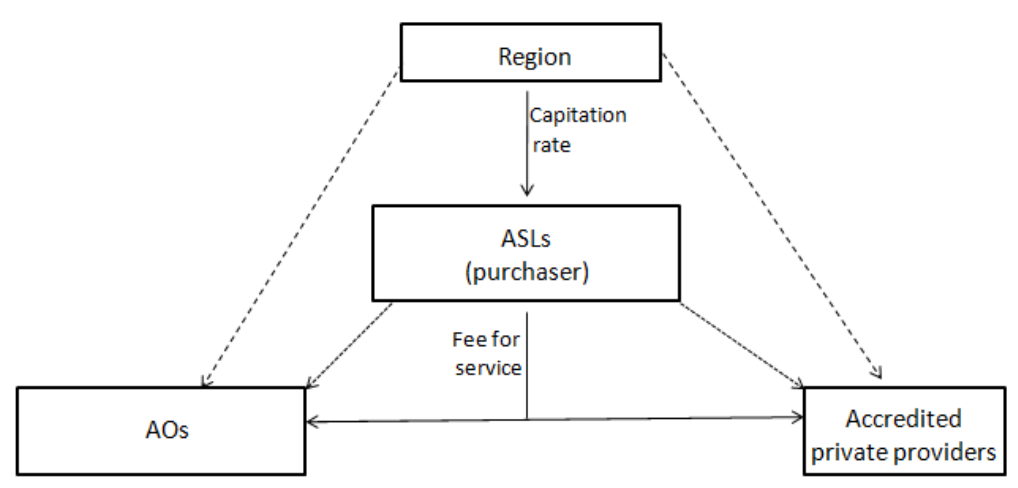

- - - - -

Funding flow and criteria

Bilateral contracts (ASLs/AOs, accredited private providers) 
Fig. 2. Boostrap estimes of $95 \%$ confidences intervals, by organizational models.

\section{Model $A$}
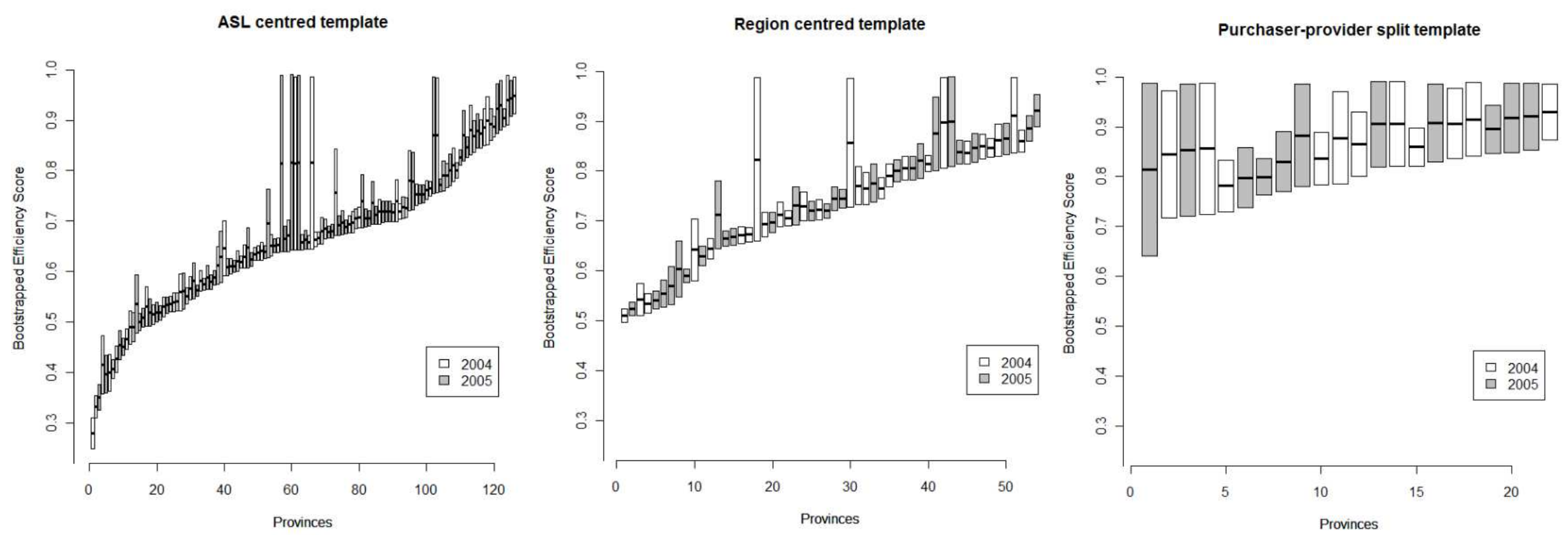
Model $C$

ASL centred template

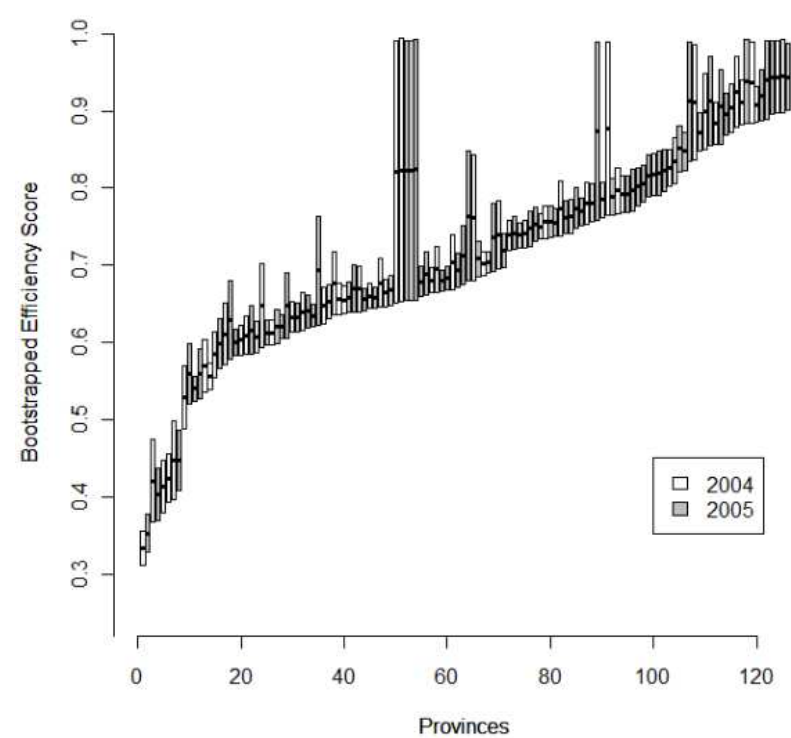

Region centred template

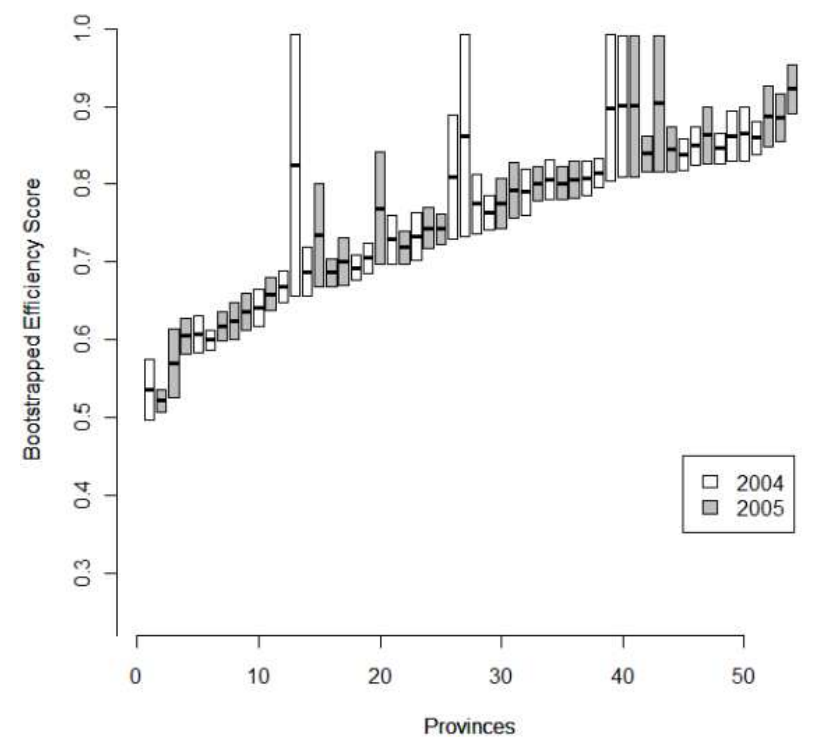

Purchaser-provider split template

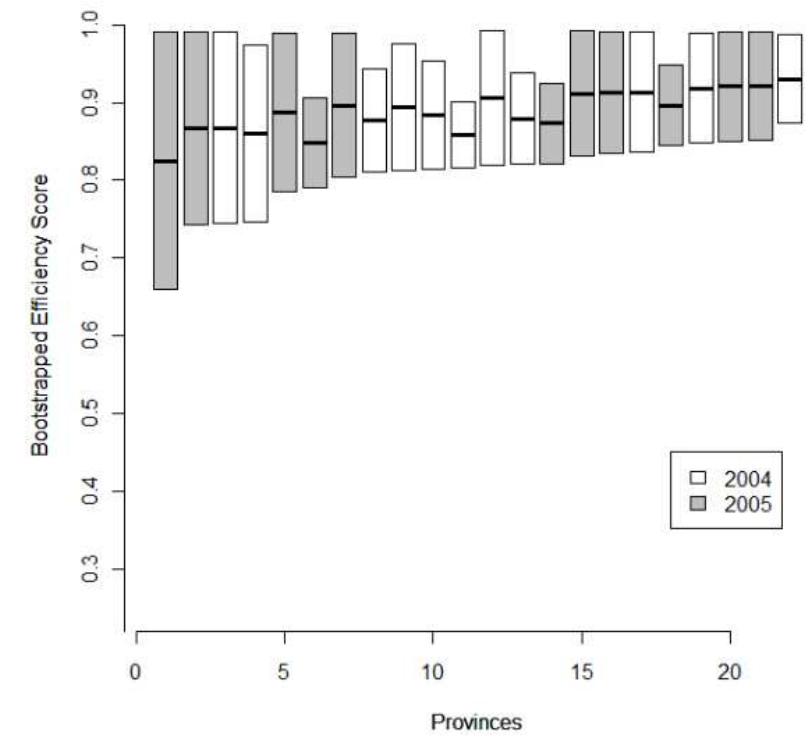




\section{Table 1}

Regional differences, 2005.

\begin{tabular}{|c|c|c|c|c|c|c|c|}
\hline Region & $\begin{array}{l}\text { Organizational } \\
\text { model }\end{array}$ & $\begin{array}{c}\text { Reimbursement } \\
\text { system }\end{array}$ & $\begin{array}{c}\mathrm{SNN}^{\mathrm{a}} \\
\text { expenditure } \\
\text { per capita }\end{array}$ & $\begin{array}{l}\text { Hospital } \\
\text { beds per } \\
\text { capita \% }\end{array}$ & $\begin{array}{l}\text { Number } \\
\text { of ASLs }\end{array}$ & $\begin{array}{c}\text { Interregional } \\
\text { patients } \\
\text { outflow }\end{array}$ & $\begin{array}{l}\text { Interregional } \\
\text { patients } \\
\text { inflow }\end{array}$ \\
\hline Piemonte & ASL cent. & Cost adjusted & 1,655 & 0.33 & 22 & 8.43 & 7.29 \\
\hline V. Aosta & ASL cent. & National & 1,857 & 0.56 & 1 & 22.17 & 12.16 \\
\hline Lombardia & $\begin{array}{l}\text { Purchaser- } \\
\text { provider }\end{array}$ & Analytic & 1,575 & 0.37 & 15 & 3.9 & 9.83 \\
\hline Bolzano & ASL cent. & National & 2,076 & 0.41 & 4 & 4.58 & 11.47 \\
\hline Trento & ASL cent. & National & 1,721 & 0.4 & 1 & 17.78 & 11.45 \\
\hline Veneto & ASL cent.. & Analytic & 1,616 & 0.4 & 21 & 5.31 & 9.32 \\
\hline Friuli & Regional cent. & National & 1,658 & 0.36 & 6 & 6.34 & 9.35 \\
\hline Liguria & Regional cent. & National & 1,833 & 0.46 & 5 & 11.19 & 12.49 \\
\hline Emilia R. & ASL cent. & Analytic & 1,686 & 0.39 & 11 & 6.31 & 13.88 \\
\hline Toscana & ASL cent. & Analytic & 1,637 & 0.37 & 12 & 5.92 & 11.3 \\
\hline Umbria & ASL cent. & Analytic & 1,618 & 0.25 & 4 & 11.28 & 15.16 \\
\hline Marche & ASL cent. & National & 1,542 & 0.35 & 13 & 10.75 & 9.57 \\
\hline Lazio & ASL cent. & Analytic & 1,816 & 0.37 & 12 & 6.64 & 9.32 \\
\hline Abruzzo & Regional cent. & National & 1,700 & 0.36 & 6 & 10.2 & 13.38 \\
\hline Molise & Regional cent. & National & 1,854 & 0.49 & 4 & 20.62 & 24.64 \\
\hline Campania & Regional cent. & National & 1,603 & 0.25 & 13 & 7.55 & 2.86 \\
\hline Puglia & ASL cent. & National & 1,432 & 0.33 & 12 & 7.64 & 4.24 \\
\hline Basilicata & ASL cent. & National & 1,477 & 0.36 & 5 & 24.01 & 12.58 \\
\hline Calabria & ASL cent. & National & 1,404 & 0.27 & 11 & 14.82 & 4.42 \\
\hline Sicilia & Regional cent. & Cost adjusted & 1,556 & 0.32 & 9 & 6.09 & 2.09 \\
\hline Sardegna & ASL cent. & National & 1,593 & 0.9 & 8 & 4.24 & 2.24 \\
\hline ITALIA & & & 1,622 & 0.39 & 195 & 7.29 & 8.16 \\
\hline NORTH & & & 1,960 & 0.38 & 86 & 6.08 & 10.31 \\
\hline CENTRE & & & 1,653 & 0.36 & 41 & 7.33 & 10.34 \\
\hline SOUTH & & & 1,577 & 0.35 & 68 & 8.52 & 4.58 \\
\hline
\end{tabular}

\footnotetext{
Source: Ministry of Health.
} 
Table 2

Summary of the models.

\begin{tabular}{|c|c|c|c|c|c|}
\hline & & Model $A$ & Model $B$ & Model $C$ & Model $D$ \\
\hline \multirow{7}{*}{$\begin{array}{c}\text { DEA } \\
\text { analysis }\end{array}$} & Inputs: & & & & \\
\hline & Physicians & $x$ & $x$ & $x$ & $x$ \\
\hline & Beds & $x$ & $x$ & $x$ & $x$ \\
\hline & Nurses & $x$ & $x$ & $x$ & $x$ \\
\hline & Outputs: & & & & \\
\hline & Num. total patients & $x$ & $x$ & $x$ & $x$ \\
\hline & Num. inpatient days & & & $x$ & $x$ \\
\hline \multirow{5}{*}{$\begin{array}{c}\text { Two stage } \\
\text { analysis }\end{array}$} & Organizational models & $x$ & $x$ & $x$ & $x$ \\
\hline & $\begin{array}{l}\text { Reimbursement } \\
\text { systems }\end{array}$ & & & $\mathrm{x}$ & $\mathrm{X}$ \\
\hline & Total mobility & $x$ & & $x$ & \\
\hline & Interregional mobility & & $x$ & & $x$ \\
\hline & Year & $x$ & $x$ & $x$ & $x$ \\
\hline
\end{tabular}

Table 3

Descriptive statistics for DEA inputs and outputs and patient mobility.

\begin{tabular}{|c|c|c|c|c|c|c|}
\hline DEA analysis & \multicolumn{2}{|c|}{ Mean } & \multicolumn{2}{|c|}{ Std. Dev. } & \multicolumn{2}{|c|}{ Median } \\
\hline Physicians & \multicolumn{2}{|c|}{1666} & \multicolumn{2}{|c|}{1893.79} & \multicolumn{2}{|c|}{1082} \\
\hline Beds & \multicolumn{2}{|c|}{2113} & \multicolumn{2}{|c|}{2386.25} & \multicolumn{2}{|c|}{1296} \\
\hline Nurses & \multicolumn{2}{|c|}{3842} & \multicolumn{2}{|c|}{3726.09} & \multicolumn{2}{|c|}{2647} \\
\hline Num. total patients & \multicolumn{2}{|c|}{104900} & \multicolumn{2}{|c|}{128005.5} & \multicolumn{2}{|c|}{61640} \\
\hline Num. inpatient day & \multicolumn{2}{|c|}{522000} & \multicolumn{2}{|c|}{632489.5} & \multicolumn{2}{|c|}{332300} \\
\hline \multirow{2}{*}{$\begin{array}{l}\text { Two stage } \\
\text { analysis }\end{array}$} & \multicolumn{2}{|c|}{$\begin{array}{l}\text { ASL centred } \\
\text { template }\end{array}$} & \multicolumn{2}{|c|}{$\begin{array}{l}\text { Region centred } \\
\text { template }\end{array}$} & \multicolumn{2}{|c|}{$\begin{array}{l}\text { Purchaser-provider } \\
\text { split template }\end{array}$} \\
\hline & Mean & Std. Dev. & Mean & Std. Dev. & Mean & Std. Dev. \\
\hline Total patients outflow & 22.75 & 10.40 & 24.93 & 13.61 & 22.81 & 10.34 \\
\hline Total patients inflow & 18.16 & 7.77 & 19.09 & 9.19 & 20.3 & 5.00 \\
\hline $\begin{array}{l}\text { Interregional patients } \\
\text { outflow }\end{array}$ & 9.52 & 5.80 & 9.94 & 5.49 & 4.44 & 3.98 \\
\hline $\begin{array}{l}\text { Interregional patients } \\
\text { inflow }\end{array}$ & 8.67 & 4.82 & 7.83 & 8.50 & 7.2 & 4.21 \\
\hline
\end{tabular}




\section{Table 4}

Simar-Zelenyuk-adapted-Li test for equality of efficiency distributions.

\begin{tabular}{llcc}
\hline & Null hypothesis & Test statistics & Bootstrap p-value \\
\hline Model A-B & $\mathrm{f}\left(\mathrm{eff}^{\mathrm{PPST}}\right)=\mathrm{f}\left(\mathrm{eff}^{\mathrm{RCT}}\right)$ & 2.629 & 0.001 \\
& $\mathrm{f}\left(\mathrm{eff}^{\mathrm{PPST}}\right)=\mathrm{f}\left(\mathrm{eff}^{\mathrm{ACT}}\right)$ & 4.468 & 0.000 \\
\multirow{3}{*}{ Model C-D } & $\mathrm{f}\left(\mathrm{eff}^{\mathrm{ACT}}\right)=\mathrm{f}\left(\mathrm{eff}^{\mathrm{RCT}}\right)$ & 2.693 & 0.027 \\
& $\mathrm{f}\left(\mathrm{eff}^{\mathrm{PPST}}\right)=\mathrm{f}\left(\mathrm{eff}^{\mathrm{RCT}}\right)$ & 2.629 & 0.000 \\
& $\mathrm{f}\left(\mathrm{eff}^{\mathrm{PPST}}\right)=\mathrm{f}\left(\mathrm{eff}^{\mathrm{ACT}}\right)$ & 4.468 & 0.000 \\
& $\mathrm{f}\left(\mathrm{eff}^{\mathrm{ACT}}\right)=\mathrm{f}\left(\mathrm{eff}^{\mathrm{RCT}}\right)$ & 2.693 & 0.024
\end{tabular}

Notes: $\mathrm{f}(\mathrm{eff})=$ the distribution of efficiency scores, PPST $=$ Purchaser-provider split template, ACT $=$ ASL Centred template, RCT $=$ Region centred template. The number of bootstrap iterations is 1000 . 
Table 5

Second stage results.

\begin{tabular}{|c|c|c|c|}
\hline & Estimates & Lower & Upper \\
\hline \multicolumn{4}{|l|}{ Model $A$} \\
\hline Intercept & 0.359 & -0.117 & 0.880 \\
\hline Total patients outflow & $0.019^{\mathrm{c}}$ & 0.012 & 0.026 \\
\hline Total patients inflow & $-0.015^{\mathrm{a}}$ & -0.027 & -0.002 \\
\hline ASL centred template & $0.481^{\mathrm{b}}$ & 0.222 & 0.717 \\
\hline $\begin{array}{l}\text { Purchaser-provider split } \\
\text { template }\end{array}$ & $-1.986^{b}$ & -2.894 & -0.605 \\
\hline Year & $0.392^{\mathrm{c}}$ & 0.178 & 0.584 \\
\hline Variance & $0.463^{\mathrm{c}}$ & 0.384 & 0.584 \\
\hline \multicolumn{4}{|l|}{ Model $B$} \\
\hline Intercept & 0.208 & -0.262 & 0.810 \\
\hline Interregional patients outflow & $0.048^{\mathrm{c}}$ & 0.027 & 0.067 \\
\hline Interregional patients inflow & $-0.028^{a}$ & -0.046 & -0.004 \\
\hline ASL centred template & $0.461^{\mathrm{b}}$ & 0.161 & 0.704 \\
\hline $\begin{array}{l}\text { Purchaser-provider split } \\
\text { template }\end{array}$ & $-2.058^{a}$ & -3.080 & -0.422 \\
\hline Year & $0.456^{\mathrm{b}}$ & 0.209 & 0.679 \\
\hline Variance & $0.490^{\mathrm{c}}$ & 0.383 & 0.592 \\
\hline \multicolumn{4}{|l|}{ Model $C$} \\
\hline Intercept & $0.515^{\mathrm{c}}$ & 0.168 & 0.900 \\
\hline Total patients outflow & $0.012^{\mathrm{c}}$ & 0.007 & 0.017 \\
\hline Total patients inflow & $-0.012^{b}$ & -0.020 & -0.003 \\
\hline ASL centred template & $0.320^{\mathrm{c}}$ & 0.015 & 0.490 \\
\hline $\begin{array}{l}\text { Purchaser-provider split } \\
\text { template }\end{array}$ & $-1.464^{b}$ & -2.213 & -0.470 \\
\hline Year & $0.292^{c}$ & 0.161 & 0.427 \\
\hline National & $0.331^{\mathrm{b}}$ & 0.132 & 0.517 \\
\hline Analytic & -0.047 & -0.267 & 0.151 \\
\hline Variance & $0.336^{\mathrm{c}}$ & 0.289 & 0.405 \\
\hline \multicolumn{4}{|l|}{ Model $D$} \\
\hline Intercept & $0.462^{b}$ & 0.102 & 0.871 \\
\hline Interregional patients outflow & $0.025^{\mathrm{b}}$ & 0.011 & 0.039 \\
\hline Interregional patients inflow & $-0.029^{b}$ & $-0,044$ & -0.011 \\
\hline ASL centred template & $0.294^{b}$ & 0.105 & 0.466 \\
\hline $\begin{array}{l}\text { Purchaser-provider split } \\
\text { template }\end{array}$ & $-1.768^{b}$ & -2.659 & -0.503 \\
\hline Year & $0.342^{c}$ & 0.179 & 0.504 \\
\hline National & $0.352^{b}$ & 0.104 & 0.570 \\
\hline Analytic & 0.050 & -0.224 & 0.286 \\
\hline Variance & $0.371^{\mathrm{c}}$ & 0.303 & 0.449 \\
\hline
\end{tabular}

${ }^{\mathrm{a}}$ Statistically significant at $10 \%$. ${ }^{\mathrm{b}}$ Statistically significant at $5 \%$. ${ }^{\mathrm{c}}$ Statistically significant at $1 \%$. Estimates, Lower and Upper denotes the Estimates, the Lower bound and the Upper bound for 90-percent confidence intervals obtained by bootstrapping. 